\title{
BROAD SPECTRUM
}

Dear Reader,

What will cars look like in the next 10 to 20 years? Which powertrains and which features will dominate the market in which models? These questions sound complicated, which indeed they are. It is clear that current and future emissions legislation will result in considerable electrification of powertrains. But as the automotive industry cannot rely on battery-powered cars, hybrid drive systems using modular internal combustion engines will gain outstanding importance over the next 10 to 15 years.

It is also clear that cars will continue to be strongly influenced by emotions. But there will be a shift in this emotional component. Even if electrification does not mean a loss of sportiness, it is obvious that the "i-phone generation" will no longer necessarily attach great importance to engine size or power output. In a few years' time, it will be the availability of IT features from the category of car-to-internet and cloud-based communication that will also influence the choice of model or brand. Added to this, a variety of driver assistance systems, not only ones that support longitudinal and lateral dynamics but also numerous other "little helpers", are likely to serve as differentiating features.

The spectrum strategies of car makers show that they are striving to fill as many small niches as possible, with regard to the technical properties of internal combustion engines, hybridisation and IT features. At first glance, it might seem as if car makers, suppliers and service providers have no idea what is going to happen. Ultimately, however, developments in $\mathrm{CO}_{2}$ reduction technologies - due to legislation - are highly dynamic. The same is true for the IT sector. This makes it necessary, particularly for full-size manufacturers, to play on different stages at the same time. Politicians would be well advised to take a step back and give manufacturers - and not least their customers - a chance to assess their positions.

Developments in the automotive sector have hardly ever been so exciting and dynamic. But what is most exciting of all is the question of what tomorrow's customer will want. This means taking a leading role today to avoid a "me too" effect in the future - and to ensure that the customer of tomorrow is already being made aware of a brand's value today.

Best regards,

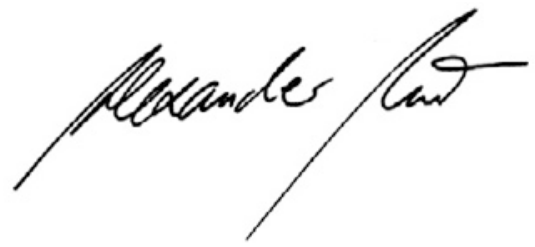

DR. ALEXANDER HEINTZEL, Editor in Chief Wiesbaden, 28 January 2013

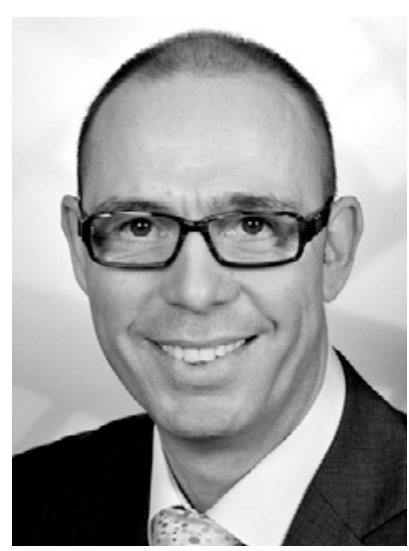

